\title{
PENINGKATAN PEMAHAMAN KONSEP MENGGUNAKAN LEMBAR KERJA MAHASISWA PADA MATA KULIAH INOVASI PEMBELAJARAN IPA DI KAMPUS CEMARA
}

\author{
Dyah Ayu Fajarianingtyas ${ }^{1}$, Herowati $^{2}$ \\ Universitas Wiraraja ${ }^{1,2}$ \\ dyahayu@wiraraja.ac.id ${ }^{1}$, heromukmin@yahoo.com ${ }^{2}$
}

\begin{abstract}
ABSTRAK
Pengembangan bahan ajar yang tepat dan sesuai kebutuhan mahasiswa adalah salah satu upaya terbaik untuk meningkatkan hasil belajar. Oleh karena itu bahan ajar merupakan hal yang sangat penting untuk dikembangkan sebagai upaya meningkatkan kualitas pembelajaran.. Tujuan penelitian adalah mengetahui peningkatan pemahaman konsep mahasiswa menggunakan Lembar Kerja Mahasiswa (LKM) mata kuliah Inovasi Pembelajaran IPA. Penelitian ini menggunakan rancangan One Group Pretest-Posttest Design. Sampel penelitian sebanyak 30 mahasiswa yang memprogram mata kuliah inovasi pembelajaran IPA. Hasil penelitian menunjukan bahwa nilai pretes adalah 0.983; dan nilai posttes adalah 0.814, hasil gain score 0,38 (kategori sedang). Kesimpulan penelitian ini adalah ada peningkatan pemahaman konsep sebesar 0,38 (kategori sedang) dilihat dari nilai rata-rata gain score.
\end{abstract}

Kata Kunci: Lembar Kerja Mahasiswa (LKM), pemahaman konsep, inovasi pembelajaran

\section{ABSTRACT}

The development of appropriate teaching materials and according to student needs is one of the best efforts to improve learning outcomes. Therefore teaching materials are very important things to be developed as an effort to improve the quality of learning. The aimed of the study is to know the increase in understanding of students using Student Worksheets (MFIs) in Science Learning Innovation courses. This study used the design of One Group Pretest-Posttest Design. The research sample consisted of 30 students who programed science learning innovation courses. The results showed that the pretest value was 0.983; and the post-test value is 0.814, the gain score is 0.38 (medium category). The conclusion of this study is that there is an increase in understanding of the concept by 0.38 (medium category) seen from the gain score average value.

Keywords: Student Worksheets (LKM), concept understanding, learning innovation

\section{PENDAHULUAN}

Pendidikan dengan paradigma pembelajaran abad 21 merupakan proses yang dapat melahirkan individu yang berbekal pengetahuan, keterampilan, dan nilai-nilai yang diperlukan untuk hidup dan berkiprah dalam era globalisasi. Manusia dapat menggunakan akal pikiran (melakukan aktivitas berpikir) dan menguasai ilmu pengetahuan dan teknologi (IPTEK). Oleh karena itu, belajar menjadi sebuah konsekuensi dari aktivitas menuntut ilmu.
Perbedaan paradigma pembelajaran berdampak pada hasil belajar peserta didik. Pembelajaran di Indonesia umumnya berpusat pada guru. Sementara itu, hasil tes TIMSS dan PISA memperoleh hasil paradigma guru di Jepang percaya bahwa peserta didik akan belajar dengan baik apabila dimulai dengan berupaya menyelesaikan permasalahan yang menantang dan kompleks, kemudian berdiskusi bersama untuk memecahkan permasalahan (Sani, 2016). 
Dosen dapat membantu mahasiswa mempelajari informasi dengan cara yang akan memungkinkannya berguna dan juga bermakna bagi mereka. Pengajaran yang efektif memerlukan pemahaman tentang bagaimana membuat informasi dapat diakses bagi mahasiswa sehingga mereka dapat menghubungkannya dengan informasi lain, memikirkannya, dan menerapkannya di luar ruang kelas (Slavin, 2011).

Pemahaman konsep merupakan salah satu indikator keberhasilan belajar kognitif. Motivasi mahasiswa untuk mengingat materi melalui pemahaman. Penyandian sebagian besar informasi ke memori dapat dilakukan dengan memberikan konsep dan ide dengan pengalaman dan makna personal. Mahasiswa dapat belajar dengan latihan-latihan untuk mengelaborasi suatu konsep agar dapat memproses informasi secara lebih mendalam (Santrock, 2008). Aktivitas mahasiswa dalam Pembelajaran Ilmu Pengetahuan Alam (IPA) untuk membangun pengetahuan konseptual meliputi membaca teks, menghadiri presentasi atau demonstrasi, membuat catatan, mengamati benda, berdiskusi, berpartisipasi dalam simulasi, mengeksplorasi topik, mempelajari istilah, mengobservasi fenomena, membedakan pengamatan dengan inferensi, mengembangkan prediksi, hipotesis, dan variabel; memilih prosedur, menata prosedur; mengorganisasi data; menganalisis data; membandingkan temuan dengan prediksi atau hipotesis; dan membuat hubungan antara temuan dan konsep (Sani, 2016).

Hasil observasi pada perkuliahan Inovasi Pembelajaran IPA tahun akademik 2016-2017, sebagian mahasiswa melakukan diskusi bersifat hafalan text book tanpa berupaya mengkaitkan kehidupan sehari-hari sehingga pemahaman konsep pembelajaran IPA yang bermakna belum tergali secara maksimal. Salah satu faktor penyebab adalah kurang tersedianya bahan ajar alternatif yang menuntut aktivitas mahasiswa untuk melakukan inovasi pembelajaran IPA. Hasil penelitian Rohadi (2013) bahwa hasil belajar rata-rata mahasiswa pada LKM untuk siklus 1 adalah 3,60 pada siklus 2 sebesar 3,75 dan pada siklus 3 adalah 3,90 dengan nilai ratarata total sebesar 3,75 (nilai maksimum $5,00)$.

Rumusan penelitian adalah seberapa besar peningkatan pemahaman konsep setelah menggunakan LKM?

\section{METODE}

Penelitian ini menggunakan rancangan One Group Pretest and Posttest Design. Penelitian ini menggunakan satu kelompok mahasiswa yang terdiri atas kelompok mahasiswa yang belajar menggunakan Lembar Kerja Mahasiswa (LKM) mata kuliah Inovasi Pembelajaran IPA. Untuk melihat peningkatan pemahaman konsep dari nilai pretest dan posttest menggunakan Gainscore.

Desain penelitian ditunjukkan pada Tabel 1.

Tabel 1. Desain Penelitian

\begin{tabular}{cccc}
\hline Kelompok & Pretes & Perlakuan & Postes \\
\hline A & Y1 & $\mathrm{X} 1$ & Y2 \\
\hline
\end{tabular}

Keterangan:

1. $\mathrm{X} 1=$ Perlakuan menggunakan Lembar Kerja Mahasiswa (LKM)

2. $\mathrm{Y} 1=$ Skor Tes Awal

3. $\mathrm{Y} 2=$ Skor Tes Akhir

4. $\mathrm{A}=$ Kelompok Mahasiswa

Peningkatan pemahaman konsep diperoleh dari Gainscore. Teknik normalized gain ( $\mathrm{N}$-gain) yang dapat dihitung dengan menggunakan persamaan $\mathrm{N}$-gain dari persamaan Meltzer sebagai berikut.

$$
\begin{aligned}
\text { Rumus: }\langle g & >=\frac{\text { S Post-S Pre }}{\text { SMaks-SPre }} \\
\text { dengan: }\langle\mathrm{g}>\quad & =\text { Nilai normalized gain } \\
\text { S post } & =\text { Skor post test } \\
\text { S pre } & =\text { Skor pre test } \\
\text { S maks } & =\text { Skor maksimum ideal }
\end{aligned}
$$

dengan kategori perolehan $\mathrm{N}$-gain seperti pada Tabel 2. 
Tabel 2. Kategori Perolehan Skor N-Gain

\begin{tabular}{cc}
\hline Batasan & Kategori \\
\hline $\mathrm{g}>0,7$ & Tinggi \\
\hline $0,3 \leq \mathrm{g} \leq 0,7$ & Sedang \\
\hline $\mathrm{g}<0,3$ & Rendah \\
\hline
\end{tabular}

\section{HASIL}

Hasil Gain-score didapatkan bahwa nilai rata-rata sebesar 0,38 termasuk kategori sedang. Artinya ada peningkatan pemahaman konsep Lembar Kerja Mahasiswa (LKM) sebesar 0,38.

\section{PEMBAHASAN}

Peningkatan sebesar 0,38 (kategori sedang) dilihat dari nilai rata-rata gain score. Hal ini dikarenakan bahwa tugastugas yang dirancang dalam LKM memuat langkah pembelajaran yang mendorong mahasiswa untuk berpikir kritis dan kreatif dalam hal merancang keefektifan pembelajaran. Penyusunan LKM dapat meningkatkan kemampuan berpikir kritis dan kreatif dengan melatih keterampilan mahasiswa memecahkan masalah dikaitkan dengan wilayah Pesisir sesuai kondisi kampus Cemara yang terletak di wilayah pesisir. Hal ini sesuai dengan pernyataan Santrock (2008) bahwa salah satu strategi dalam membantu mahasiswa membentuk konsep adalah mengecek pemahaman konsep dan memotivasi mahasiswa untuk mengaplikasikasikan konsep dalam konteks lain.

Penggunaan LKM dalam mata kuliah inovasi Pembelajaran IPA memuat informasi pendukung sehingga aktivitas pembelajaran menuntut mahasiswa melakukan pemecahan masalah terutama yang terjadi di wilayah pesisir sesuai dengan kondisi alam tempat mahasiswa belajar sehingga situasi belajar menjadi bermakna. Pengelolaan sumberdaya pesisir pada dasarnya memiliki tujuan untuk meningkatkan kesejahteraan seluruh masyarakat secara berkelanjutan, terutama komunitas masyarakat lokal yang bermukim di wilayah pesisir (coastal zone). Oleh karena itu, pemahaman konsep mahasiswa terbentuk melalui kegiatan pemecahan masalah yang dimuat dalam
LKM dikaitkan melalui aktivitas penduduk setempat di wilayah pesisir. Dalam proses pembelajaran IPA, mahasiswa tidak hanya sekadar menghafal teori, akan tetapi lebih ditekankan pada terbentuknya proses pemahaman konsep. Schunk (2012) menyatakan bahwa mahasiswa membentuk konsep melalui pengalaman langsung dengan objek atau kejadian dalam dunia mereka. Rancangan LKM memuat materi pembelajaran bermakna, diskusi, dan pembelajaran berorientasi SETS mendorong mahasiswa untuk aktif dalam pemecahan masalah berbasis pesisir. LKM dilengkapi dengan informasi pendukung berupa isu-isu yang sesuai dengan potensi lokal di wilayah pesisir Sumenep. LKM berbentuk media cetak, dan terdiri dari identitas, capaian pembelajaran, petunjuk, materi pembelajaran, informasi pendukung, paparan isi materi, tugas, dan penilaian.

Karakteristik dari LKM yang dirancang adalah (1) LKM memuat aktivitas mahasiswa di wilayah pesisir sesuai dengan domisili mahasiswa IPA di kampus Cemara, (2) Menjelaskan capaian pembelajaran sehingga dapat memandu mahasiswa dalam melakukan aktivitas pemecahan masalah, (3) LKM disusun dengan tugas yang mendorong mahasiswa melakukan aktivitas berpikir kritis dan berpikir kreatif baik secara mandiri atau kelompok. Slavin (2011) menyatakan bahwa pengajaran yang efektif memerlukan pemahaman tentang bagaimana membuat informasi dapat diakses bagi mahasiswa sehingga mereka dapat menghubungkannya dengan informasi lain, memikirkannya, dan menerapkannya di luar ruang kelas.

Respon positif dari mahasiswa terhadap pembelajaran dan materi merupakan faktor penting untuk diperhatikan karena materi ajar yang baik harus didasarkan pada kebutuhan dan minat mahasiswa. Penelitian ini mendapatkan hasil respon positif sebesar $87 \%$ yang menunjukkan bahwa mahasiswa di kampus Cemara senang menggunakan 
Lembar Kerja Mahasiswa (LKM) dikategorikan berhasil. Hasil penelitian sejalan dengan hasil penelitian Lestari, Suciati, \& Sugiyarto (2014) LKM efektif meningkatkan kemampuan berpikir kritis mahasiswa, dilihat dari kemampuan mahasiswa memecahkan permasalahan, dapat membangun konsep sendiri dalam proses pembelajaran, serta mampu mempresentasikan hasil karya berupa laporan hasil kegiatan.

\section{KESIMPULAN}

Ada peningkatan pemahaman konsep kelompok mahasiswa yang belajar menggunakan Lembar Kerja Mahasiswa (LKM) pada mata kuliah Inovasi Pembelajaran IPA sebesar 0,38 (kategori sedang) dilihat dari nilai rata-rata gain score.

\section{DAFTAR PUSTAKA}

Anwar, M., Setiabudi, A., \& Martoprawiro, M. A. (2012). Desain Lembaran Kerja Mahasiswa Berbasis Pembelajaran Aktif-Kooperatif untuk Meningkatkan Keterampilan Generik Sains Mahasiswa (Penerapan pada Topik Mekanisme Reaksi). Jurnal Chemica, 13(1), 1-13.

Dahar, R. (2011). Teori-teori Belajar dan Pembelajaran. Jakarta: Erlangga.

Husamah, Yuni, P., Artina, R., \& Puji, S. (2016). Belajar dan Pembelajaran. Malang: UMM Press.

Jones, V. (2012). Comprehensive classroom Management: Creating Communities of Support and Solving Problems. Jakarta: Kencana.

Lestari, N., Suciati, \& Sugiyarto. (2014). Pengembangan LKM Model PBLberbasis Potensi Lokal pada Mata Kuliah Bioteknologi untuk Meningkatkan Kemampuan Berpikir Kritis Mahasiswa Di Universitas Muhammadiyah Kupang. BIOEDUKASI, 7(2), 18-22.

Liriwati, F. Y. (2017). Pengaruh Pengelolaan Kelas terhadap Hasil Belajar Siswa. Open Jurnal System
Indragiri, 1(3), 58-69.

Maherawati, I. D. A. A. T., \& Sutardji. (2015).

KUALITAS

PENGELOLAAN KELAS DAN MOTIVASI BELAJAR GEOGRAFI SISWA KELAS XI SMA NEGERI KOTA TEGAL TAHUN PELAJARAN 2013/2014. Edu Geography, 3(5), 24-30.

Prastowo, A. (2011). Panduan Kreatif Membuat Bahan Ajar Inovatif. Jogjakarta: DIVA Press.

Rohadi, N. (2013). Pengembangan Lembar Kerja Mahasiswa Berbasis Keterampilan Berpikir Menerapkan Model Pembelajaran Berdasarkan Masalah pada Perkuliahan Medan Elektromagnet. In Prosiding Semirata. Lampung: FMIPA Universitas Lampung.

Sani, R. A. (2016). Inovasi Pembelajaran. Jakarta: PT. Bumi Aksara.

Santrock, J. W. (2008). Educational Psychology. Jakarta: Kencana Prenada Media Group.

Schunk, D. H. (2012). Learning Theories An Educational Perspective (TeoriTeori Pembelajaran: Perspektif Pendidikan). Yogyakarta: Pustaka Belajar.

Slavin, R. E. (2011). Psikologi Pendidikan Teori dan Praktik (Kesembilan). Jakarta: PT. Indeks.

Syaifurahman. (2013). Manajemen dalam Pembelajaran. Jakarta: PT. Indeks. 